\title{
FILOSOFIA POLÍTICA E DEMOCRACIA: A IMPORTÂNCIA DO ANTAGONISMO E DO CONFLITO PARA A CONSTRUÇÃO DA POLÍTICA
}

\author{
POLITICAL PHILOSOPHY AND DEMOCRACY: THE IMPORTANCE OF ANTAGONISM AND \\ CONFLICT FOR THE CONSTRUCTION OF POLITICS
}

Bruno Vicente Lippe Pasquarelli ' Flávia Santos Arielo²

\section{RESUMO}

O estudo visa contribuir com o debate sobre a democracia a partir de conceitos da filosofia política, examinando pressupostos relacionados ao consenso e ao conflito. Para tanto, evidencia-se que a tradição do pensamento da democracia consensual de Jürgen Habermas destacou o componente da deliberação e do diálogo como requisitos da política. Porém, a partir do conceito de agonismo presente na teoria de Chantal Mouffe, podemos compreender o antagonismo como possibilidade de oposição compatível com democracia pluralista, considerando componentes multiculturais e as diversas formas de identidade para auxiliar na construção de debates contra posições extremistas e que podem ocasionar práticas terroristas no plano mundial. Por conseguinte, é imprescindível o fortalecimento do debate do modelo agonista de conflito, aceitando o pluralismo e renunciando a ilusão de um mundo unificado.

Palavras-chave: Antagonismo. Conflito. Democracia. Pluralismo.

\begin{abstract}
The study aims to contribute to the debate about democracy from concepts of political philosophy, examining assumptions related to consensus and conflict. For this, it is evident that the tradition of the thought of the consensual democracy of Jürgen Habermas emphasized the component of the deliberation and the dialogue as requirements of the policy. However, from the concept of agonism present in Chantal Mouffe's theory, we can understand antagonism as a possibility of opposition compatible with pluralistic democracy, considering multicultural components and the different forms of identity to aid in the construction of debates against extremist positions and that can cause Terrorist practices worldwide. Therefore, it is essential to strengthen the debate of the agonist model of conflict, accepting pluralism and renouncing the illusion of a unified world.
\end{abstract}

Keywords: Antagonism. Conflict. Democracy. Pluralism.

\section{INTRODUÇÃO}

A teoria democrática, baseada em ideais da filosofia política, vem constantemente buscando acompanhar as mudanças políticas, econômicas e sociais principalmente nos três últimos séculos - em decorrência das diversas revoluções pelas quais o mundo passou. Atualmente, muito tem se falado do

\footnotetext{
${ }^{1}$ Doutor em Ciência Política pela Universidade Federal de São Carlos (São Carlos/Brasil). Professor na Universidade do Sagrado Coração (Bauru/Brasil). E-mail: brunopasqua@gmail.com.

${ }^{2}$ Mestre em Ciências da Religião pela Pontifícia Universidade Católica de São Paulo (São Paulo/Brasil). Professora na Universidade do Sagrado Coração (Bauru/Brasil). E-mail: flarielo@yahoo.com.br.
} 
papel da teoria democrática nas sociedades ocidentais e orientais, pois a democracia é contestável e há uma necessidade constante de reavaliá-la.

Com o fim da União Soviética e o desmantelamento da esquerda, o neoliberalismo parecia reinar de modo incontestável como a ideologia dominante em escala global. Para muitos sociólogos, filósofos e cientistas políticos, os conflitos pertenceriam ao passado, sendo que o consenso poderia ser obtido através do diálogo. E graças à globalização e a universalização da democracia liberal, poderíamos antecipar um futuro cosmopolita que traria paz, prosperidade e implementação dos direitos humanos a todos.

No entanto, nas últimas décadas, houve algumas iniciativas por um grupo de pensadores rotulados como pós-modernos para repensar esse domínio neoliberal. No campo pós-moderno, foi lançado um ataque contra a metafísica centrada no sujeito e contra o conceito de um macrossujeito que totaliza populações inteiras, violando, assim os modos intrínsecos do outro.

O ataque ao macrossujeito populista foi iniciado por Laclau e Mouffe (1985), que direcionaram suas críticas às agendas totalizantes da esquerda política, questionando o papel de uma identidade coletiva. Para os autores, o desafio da atualidade seria enfrentar tanto a crise da democracia quanto do socialismo real, sendo necessário reformular o individualismo burguês, repensando a noção de agente individual.

Influenciada pelas ideias de Schmitt (1998), Mouffe (2009) considera que a visão da democracia liberal se nega a reconhecer a dimensão antagônica constitutiva do político. Com isso, a autora ataca os defensores da forma consensual de democracia - em especial, Jürgen Habermas - examinando as consequências da negação do antagonismo. Para Mouffe (2009), o consenso racional colocou o pensamento democrático no caminho equivocado. Isso porque no lugar de desenhar instituições que reconciliariam os interesses e valores em conflito, os teóricos e políticos democráticos deveriam promover a criação de uma esfera pública de luta agonista, onde se podem confrontar diferentes projetos políticos hegemônicos - condição sine qua non para o exercício efetivo da democracia. Nesse sentido, o enfoque consensual não cria condições para a reconciliação da sociedade, mas conduz à emergência de antagonismos.

A partir desses pressupostos, o artigo destaca a importância do pensamento da democracia consensual, mas reitera que o antagonismo deve existir, visando estabelecer posicionamentos opostos e compatíveis com o conceito de democracia pluralista, evidenciando, para tanto, componentes multiculturais, bem como as diversas formas de identidades presentes na sociedade. Desta forma, em primeiro lugar, será feita uma breve análise da teoria do consenso e da democracia deliberativa de Jürgen Habermas, assim como alguns pressupostos da teoria do reconhecimento de Axel Honneth e Nancy Fraser. Para tanto, serão utilizados e analisados conceitos baseados na democracia deliberativa e consensual de Jürgen Habermas a partir de suas três obras centrais, quais sejam, "Teoria de la Acción Comunicativa", "Mudança Estrutural de Esfera Pública" e "A inclusão do outro".

Em segundo lugar, a partir dos trabalhos de Mouffe e de outros pensadores pós-modernos, serão observadas as principais críticas ao modelo consensual de Habermas, inserindo o debate democrático a partir das novas características da sociedade atual, abordando alguns dilemas que afligem a democracia moderna e contemporânea, considerando aspectos ligados ao multiculturalismo e às novas identidades. Para esta etapa do trabalho, serão discutidos termos ligados à pós-modernidade da política, como a noção de antagonismo, conflito, agonismo e pluralidade de identidades, examinando os pressupostos teóricos centrais contidos em "A Identidade cultural na pós-modernidade", de Stuart Hall, e "En torno a lo 
político", de Chantal Mouffe, bem como a importância de se discutir tais temas em momentos tão delicados de posições extremistas na arena político-social. Por fim, serão tecidas as considerações finais.

\section{A DEMOCRACIA CONSENSUAL DE hABERMAS: A DELIBERAÇÃO E A AÇÃO COMUNICATIVA}

Nas sociedades modernas atuais, a diferenciação social é uma característica necessária. E o fortalecimento da diferenciação social nos leva a Habermas $(2001,2003,2004)$ e sua teoria social, na qual as principais temáticas são a recuperação de um conceito de interação ligado à arena social, onde a ação comunicativa vigora, além do desenvolvimento de uma concepção de diferenciação social capaz de permitir a reelaboração dos conceitos weberiano e marxiano de burocratização e de monetarização.

Habermas $(2001,2003)$ afirma a importância da linguagem, pois é na racionalidade comunicativa, voltada para o entendimento mútuo, que os sujeitos atualizam e reconfiguram o mundo. Em sua perspectiva, a sociedade deve ser compreendida a partir de uma divisão entre sistemas funcionais (onde atua a racionalidade instrumental, dividida em dois subsistemas: o econômico, regido pelo dinheiro e pelo mercado, e o político, baseado no Estado) e mundo da vida - onde impera o uso comunicativo da linguagem em interações simbolicamente mediadas que visam ao entendimento mútuo. Nesse tipo de interação, os interlocutores utilizam a linguagem visando o estabelecimento não-coercitivo de relações intersubjetivas.

Pode-se dizer que o ponto de partida da teoria social de Habermas é o paradigma da comunicação, onde há a suposição de que a utilização pragmática da linguagem é orientada para o consenso - ou seja, a ação deve ser orientada para o entendimento dos sujeitos. A possibilidade desse consenso é constatada no fato de que os indivíduos agem assumindo diferentes atitudes objetivas, subjetivas e sociais sendo que, ao agir em cada uma dessas dimensões, o ator social necessita alcançar consenso com outros indivíduos. Ou seja: a ação comunicativa se baseia em um processo cooperativo de interpretação em que os participantes se referem simultaneamente a algo em um mundo objetivo, no mundo social e no mundo subjetivo - sempre contando com a possibilidade da sua validação por outro ator. Sendo assim, a ação comunicativa supõe a precedência de uma dimensão interativa na qual os indivíduos formam suas identidades e tornam-se capazes de entender o sentido das suas ações.

Habermas (2001) denomina essa dimensão interativa de mundo da vida - um lugar em que o falante e o ouvinte se encontram, podendo estabelecer a pretensão que suas emissões concordam com o mundo (objetivo, subjetivo e social) e exibindo os fundamentos para se chegar a um acordo. Além disso, o mundo da vida é intersubjetivo, pois a estrutura da sua realidade é comum a todos. Dessa maneira, não é composto somente de certezas culturais, mas também de componentes estruturais onde, além da cultura, há a sociedade e a personalidade - que correspondem a processos de reprodução cultural, integração social e socialização, respectivamente. Por conseguinte, a ação comunicativa não é somente um processo de entendimento nem de interpretação; é, ao mesmo tempo, um processo de interação social e de socialização. Com o meio linguístico, há a aquisição de saber cultural, o reconhecimento da integração social e a formação da identidade coletiva. E quanto mais se diferenciam os componentes estruturais do mundo da vida, mais a interação é submetida às condições de entendimento racionalmente motivado, onde o consenso baseia-se no melhor argumento.

Por fim, o ponto de partida prático e moral adotado por Habermas (2004) remete a duas dimensões da política: a primeira dimensão é o reconhecimento do outro enquanto um igual. A segunda dimensão política é a ideia de democracia. A obra de Habermas supõe uma dimensão comunicativa e interativa na 
qual os atores sociais, através da linguagem, participam de um debate racional e crítico acerca da organização normativa e política da sociedade. Sendo assim, o substrato normativo da política implica a procedimentalização da democracia em nível societário através da inclusão de todos os atores sociais enquanto membros de uma comunidade de comunicação, onde imperam os princípios de organização e legitimação (AVRITZER, 1996). É o chamado modelo deliberativo de democracia, que só ganha referência empírica quando fazemos jus à diversidade das formas comunicativas na qual se constitui uma vontade comum pela busca de equilíbrio entre interesses divergentes e do estabelecimento de acordos. Ou seja: baseia-se nas condições de comunicação sob as quais o processo político é capaz de alcançar resultados racionais, justamente por cumprir-se, em todo o seu alcance, de modo deliberativo.

Sendo assim, a análise de Habermas nos apresenta uma imagem multifacetada das sociedades modernas, onde a relação entre si de dois subsistemas que operam lógicas diferentes constitui o ponto focal para a elaboração de um diagnóstico das sociedades contemporâneas. E é no ponto de encontro entre as estruturas interativas e os subsistemas que se daria o enfrentamento central da modernidade pela sobrevivência das formas de comunicação e de interação. Habermas, portanto, defende as virtudes libertadoras de um estado ideal de sociedade de comunicação através do diálogo. Este ideal constitui, a seu ver, uma alternativa às outras formas de atividade que contribuíram para a burocratização e monetarização da sociedade, pois a comunicação se faz necessária para produzir normas que permitam aos membros de uma sociedade coordenarem as suas ações com bom entendimento.

A teoria habermasiana influenciou diversos pensadores e teorias. Dentre elas, pode-se destacar a teoria do reconhecimento de Honneth (2003) e Fraser (1997, 2001), que pensa os conflitos sociais como buscas interativas pela consideração intersubjetiva de sujeitos e coletividades. Tanto Honneth quanto Fraser dialogam com Habermas a partir do referencial da Escola de Frankfurt, se apoiando na dimensão moral e intersubjetiva da política, diagnosticando as mazelas contemporâneas e propondo uma gramática moral para a superação delas, pois a política não se restringe à luta de interesses.

Tendo como base a filosofia de Hegel, Honnet (2003) ressalta a construção relacional da identidade, argumentando que os sujeitos lutam o tempo todo por reconhecimento mútuo. E é por meio do reconhecimento intersubjetivo que os sujeitos podem garantir a plena realização de suas capacidades. Portanto, os sujeitos são forjados em suas interações e somente conseguirão formar relações positivas caso se vejam reconhecidos por outros sujeitos na interação. Já Fraser $(1997,2001)$ aponta que a justiça requer tanto a redistribuição quanto o reconhecimento. Por um lado, a redistribuição buscaria o fim da diferenciação grupal, enquanto o reconhecimento estaria calcado naquilo que é particular a um grupo. Além disso, Fraser $(1997,2001)$ propõe um modelo de reconhecimento pautado na ideia weberiana de status. De acordo com essa perspectiva, o não-reconhecimento não é explicado em termos da identidade, mas como subordinação social. A partir desse viés, a luta por reconhecimento não procura a valorização da identidade, mas a superação da subordinação. Como? Através da mudança de valores e de instituições reguladoras das instituições, o que varia em cada situação.

Tanto Habermas quanto Honneth e Fraser utilizam a noção de intersubjetividade. Habermas (2001) ressalta o potencial do uso da linguagem, que ganha visibilidade em uma multiplicidade de arenas intersubjetivas, cuja trama configura uma esfera pública capaz de gerar um poder comunicativo que pode influenciar as instâncias formais de decisão política. Honneth (2003) também destaca o papel das lutas intersubjetivas - pois é por meio das lutas, individuais ou coletivas, que as pessoas são reconhecidas. Já para Fraser (1997, 2001), as políticas eficazes que combinam distribuição econômica e reconhecimento cultural não podem ser feitas sem a participação das pessoas em processos dialógicos. 
Portanto, a teoria habermasiana da ação comunicativa influenciou a teoria do reconhecimento, pois a questão da intersubjetividade e dos processos dialógicos se tornaram essenciais para ambas. No entanto, o modelo consensual de democracia não criou condições para a realização de uma sociedade reconciliada e conduziu à emergência de antagonismos (MOUFFE, 2009). Isso porque o racionalismo do modelo consensual não observou a questão do conflito tal como deveria ser analisada. E reconhecer a impossibilidade de erradicar a dimensão conflitual da vida social é a condição necessária para compreender o desafio que enfrenta a política democrática.

\section{NOVAS CONCEPÇÕES DE DEMOCRACIA: A POLÍTICA ADVERSARIAL}

A incapacidade de perceber de um modo político os problemas da sociedade é um dos grandes problemas da atualidade. E para Mouffe (2009), essa incapacidade para se pensar politicamente se deve, em grande medida, à hegemonia do liberalismo ${ }^{3}$. Com isso, é necessário demonstrar a deficiência central do liberalismo no campo político: sua negação do antagonismo. O pensamento liberal é caracterizado pelo enfoque racional e individual, impedindo de reconhecer a natureza das identidades coletivas e o pluralismo do mundo social - onde existem conflitos. Além disso, a compreensão liberal de pluralismo afirma que vivemos em um mundo no qual existem diversos valores e perspectivas que nunca poderemos adotar em sua totalidade. Por isso, o liberalismo se vê obrigado a negar o político em sua dimensão antagônica.

Em sua obra clássica El concepto de lo político, Carl Schmitt (1988) destaca que o individualismo presente na concepção liberal gera a negação do "político", excluindo a compreensão da natureza das identidades coletivas através da discriminação amigo/inimigo. Tal fato que impede que o "político" seja compreendido por meio do racionalismo liberal, pois ele é negado em sua dimensão antagônica.

Atualmente, existem dois paradigmas liberais principais: o agregativo, que concebe a política como o estabelecimento de um compromisso entre diferentes forças em conflito na sociedade; e o deliberativo, de Jürgen Habermas, que aspira vincular moralidade e política através da substituição da racionalidade instrumental pela comunicativa, criando no campo da política um consenso moral-racional mediante a livre discussão.

Criticando o viés liberal de Habermas e influenciada pelas ideias de Schmitt (1998), Mouffe (2009) acredita que a especificidade da política democrática não é a superação da oposição nós/eles (como pressupõe a democracia consensual), mas que é preciso traçar a distinção nós/eles de modo compatível com o reconhecimento do pluralismo. Sendo assim, o desafio para a política democrática consiste em tentar impedir o surgimento do antagonismo mediante um modo diferente de estabelecer a relação nós/eles. Porém, o antagonismo não pode ser erradicado, mas pode ser transformado de tal maneira que possibilite uma forma de oposição nós/eles que seja compatível com a democracia pluralista.

Dessa maneira, para haver uma forma de oposição nós/eles compatível com a democracia pluralista, deve existir algum vínculo entre as partes em conflito, de maneira a não tratar seus oponentes como inimigos a ser erradicados. Os oponentes não podem ser considerados estritamente como competidores ou se reconciliarem através da deliberação - pois o antagonismo seria eliminado. Então, para sustentar a permanência da dimensão antagônica de conflito, deve-se considerar uma outra relação: o agonismo.

\footnotetext{
${ }^{3}$ Deve-se partir do pressuposto de que Mouffe (2009) considera o modelo consensual de Habermas como parte da tradição da democracia liberal.
} 
O agonismo estabelece uma relação nós/eles cujas partes em conflito reconhecem a legitimidade de seus oponentes e se percebem como pertencentes à mesma associação política, compartilhando um espaço simbólico comum dentro do qual o conflito tem lugar. Por isso, o termo adversário é crucial para a política democrática, pois permite transformar antagonismo em agonismo. E na luta agonista o que está em jogo é a configuração das relações de poder em torno das quais se estrutura uma determinada sociedade: é uma luta entre projetos hegemônicos opostos que não podem reconciliar-se racionalmente.

$\mathrm{Na}$ sociedade, existem diversas paixões que movem os atores sociais. A negação em admitir as paixões é o que origina a incapacidade do enfoque racionalista para aceitar os movimentos políticos de massa - que seriam uma expressão das forças irracionais. Sendo assim, ao privilegiar o cálculo racional dos interesses (modelo agregativo) ou a deliberação moral (modelo deliberativo), a atual política democrática é incapaz de reconhecer o papel das paixões como uma das principais forças mobilizadoras no campo da política. A politização não existe sem a produção de uma representação conflitiva do mundo, o que permite que as paixões se movam politicamente, inseridas em um contexto do espectro democrático.

Nesse sentido, é crucial que a teoria democrática considere a dimensão afetiva da política para não transformar as identidades nacionais, por exemplo, em relações amigo/inimigo ${ }^{4}$. A sociedade é composta por vínculos afetivos, e não somente em termos de racionalidade

De acordo com Mouffe (2009), a maioria dos teóricos liberais se nega a admitir a dimensão antagônica da política e o papel de construção das identidades políticas. Mas uma democracia exige o enfrentamento entre posições democráticas legítimas, o que deve proporcionar formas de identificação coletivas. Nesse sentido, os antagonismos devem adquirir uma forma agonista, que não deve ser concebida em termos da oposição amigo/inimigo; e, se o consenso é necessário, também é essencial o dissenso.

\section{MODERNIZAÇÃO REFLEXIVA E POLÍTICA ADVERSARIAL}

A perspectiva pós-política de Mouffe visa desafiar a descrição de mundo feita por uma série de teóricos que anunciaram a sociedade pós-industrial e o fim do componente ideológico da democracia. De acordo Ulrick Beck e Anthony Giddens, a relação da sociedade com as instituições mudou profundamente nas últimas décadas, de maneira que a vida social progrediu de um estágio da modernidade para outro, denominado de "reflexivo", caracterizado pela emergência de uma sociedade de risco. Tal estágio promoveu o desencantamento com estruturas sociais existentes, com a perda de respeito pelas instituições e fortalecendo um modelo de política pautado pelo individualismo, tornando obsoletas as identidades coletivas.

Com a globalização e o surgimento dos meios instantâneos de comunicação global, assim como dos processos de individualização nos mais diversos setores societários, as identidades coletivas foram solapadas e os partidos políticos, bem como os sindicatos, perderam sua centralidade ao não se adaptarem às novas formas de conflito. A solução, de acordo com Beck (1997), é a subpolítica, na qual a dimensão do político não deve ser buscada em arenas tradicionais, como os partidos políticos.

Na subpolítica, o indivíduo passa a ocupar o centro do embate democrático. A solução, então, seria a criação de fóruns cujos especialistas, políticos, empresários e cidadãos buscariam um consenso sobre os modos de estabelecer formas possíveis de cooperação mútua, e onde haveria a necessidade de uma confiança validada democraticamente através da transformação dos sistemas de especialistas em

\footnotetext{
${ }^{4}$ No nacionalismo, por exemplo, a dimensão afetiva é particularmente forte.
} 
esferas públicas democráticas, nas quais os conflitos de interesse poderiam ser resolvidos mediante o diálogo público.

Giddens $(1991,1997,2002)$ enfatiza os efeitos da globalização e da maneira pela qual ela tem transformado as instituições, os papéis sociais e os relacionamentos da sociedade. A modernidade, nesse sentido, é uma forma de vida altamente reflexiva, "na qual práticas sociais são constantemente examinadas e reformadas à luz de informações sucessivas sobre estas mesmas práticas, que vão alterando assim, constitutivamente, o seu caráter" (GIDDENS, 1991, p. 38). Com consequência, vivemos em um período de "modernidade tardia", onde os indivíduos se defrontam com novas incertezas, depositando confiança em sistemas abstratos e gerenciando novos desafios e riscos. Com isso, Giddens sustenta que devemos pensar em termos de política da vida, que inclui questões ecológicas e também da natureza cambiante do trabalho, da família e da identidade pessoal e cultural. Por fim, assim como Beck, Giddens ressalta a importância da expansão do individualismo como forma de permitir um equilíbrio mais adequado entre as responsabilidades individuais e coletivas.

O fator ideológico, por conseguinte, se tornou obsoleto. Com a extinção do modelo socialista, a principal linha divisória entre direita e esquerda desapareceu, de maneira que a maioria dos novos problemas relacionados à sociedade pós-tradicional não podem mais ser expressados dentro desta divisão. Para isso, de maneira semelhante a Beck, Giddens propõe a necessidade de transformar o sistema de especialistas em esferas públicas democráticas, sustentando a necessidade de democratizar as principais instituições da sociedade, expondo-as ao debate e à refutação, onde os conflitos de interesse possam ser resolvidos mediante o diálogo público.

O principal argumento de Beck e Giddens é que nas sociedades pós-tradicionais já não encontramos identidades coletivas construídas em termos de nós/eles, pois os partidos políticos perderam relevância. Por isso, o modelo adversarial de política se tornou obsoleto e deve ser descartado. E ao declarar o fim de tal modelo, o enfoque de Beck e Giddens excluiu a possibilidade do agonismo em conflitos políticos ${ }^{5}$. No entanto, para Mouffe (2009), a noção de adversário é central para pensar a política democrática. E a diferença fundamental entre a perspectiva dialógica e a agonista é que o objetivo desta última é a profunda transformação das relações de poder existentes e o estabelecimento de uma nova hegemonia.

A democracia requer a transformação das estruturas de poder existentes e a construção de uma nova hegemonia, distinguindo categorias de antagonismo (entre inimigos) e agonismo (entre adversários) e concebendo um consenso conflitual entre oponentes. A política não deve ser concebida como um intercâmbio de opiniões, mas uma luta pelo poder. E, em uma relação de poder estabelecida, é necessário definir um adversário em uma dimensão antagônica, constitutiva do político.

\footnotetext{
${ }^{5}$ Giddens (2002) vincula a tese da modernidade reflexiva à estratégia política com a política da Terceira Via, cujo objetivo é a criação de um novo estado democrático que atue em cooperação com a sociedade civil. Para tanto, a expansão do individualismo deve ser acompanhada da ampliação das obrigações individuais, reformando o Estado e o governo no tocante à sua forma de associação com a sociedade civil. É central, então, que a esfera pública se descentralize com eficiência administrativa. No entanto, tal política ressalta a natureza não-conflitiva, eliminando a dimensão do antagonismo do político. E, como evita o conflito, a análise de Giddens é incapaz de desafiar a hegemonia do neoliberalismo. Mesmo com tais pontos negativos, as propostas de Giddens inspiraram a política do novo laborismo de Tony Blair, na Inglaterra, que promoveu a renúncia do trabalhismo à sua identidade esquerdista, onde as classes sociais desapareceram do discurso, pois buscava-se o consenso no centro do espectro ideológico.
} 


\section{POLÍTICA ADVERSARIAL NA ATUALIDADE: POPULISMO DE EXTREMA-DIREITA, TERRORISMO, DEMOCRACIA COSMOPOLITA E MULTICULTURALISMO}

Uma das principais maneiras de demonstrar as consequências da não-existência de uma forma agonista de conflito é através do fortalecimento dos partidos populistas de direita e do terrorismo. Quando não existem canais através dos quais os conflitos adotem uma forma agonista, privilegia-se o antagonismo, cuja confrontação nós/eles é visualizada a partir do aspecto moral, entre bem e mal, de maneira que o oponente somente pode ser percebido como um inimigo que deve ser destruído.

Com relação ao populismo de direita, sua expansão ocorreu em circunstâncias nas quais as diferenças entre os partidos políticos tradicionais se tornaram muito menos significativas do que no passado. Ou seja: a ausência do agonismo se encontra na incapacidade dos partidos políticos democráticos em propor alternativas significativas, diferentes do modelo do consenso da atualidade. Com isso, o discurso populista da direita substitui a debilitada oposição direita/esquerda por um novo tipo de nós/eles, construído em torno de uma oposição entre povo e establishment. Como consequência da vitória do populismo de direita em alguns países europeus 6 , a oposição nós/eles (sendo que "eles" seriam os partidos de extrema direita) se construiu segundo as categorias morais de "bem" versus "mal". Portanto, segundo Mouffe (2009), os antagonismos políticos estão sendo formulados em termos de categorias morais; e as discriminações do tipo amigo/inimigo são expressadas através da utilização do vocabulário da moralidade. Quando os oponentes são definidos em termos morais e não políticos, não podem ser concebidos como um adversário, mas somente como um inimigo.

No plano internacional, desde 2001 houve a multiplicação dos ataques terroristas. Com a tentativa de imposição de um modelo consensual e democrático para praticamente todas as formas de cultura, o terrorismo se tornou o produto de uma nova configuração do político - característica do tipo de ordem mundial que vem sendo implementada em torno da hegemonia de um hiperpoder único (SCHMITT, 1998). Com a exclusão da possibilidade de uma participação direta e formalizada no sistema internacional, os indivíduos e grupos frustrados vêm recorrendo a diversos modos de resistência, como o terrorismo.

Atualmente, podemos afirmar que, apesar de ainda termos diversos tipos de grupos terroristas nacionalistas, um outro viés surge com força: o terrorismo fundamentalista, ou seja, aquele que tem por base uma religião e deseja implantar uma moral religiosa a todo custo. A este tipo de terrorismo estão ligados grupos como o Boko Haram e o Estado Islâmico. Sua base, além de ser política, está ligada a fatores religiosos e moralistas. Os líderes representam não apenas um chefe, mas são também gurus espirituais e morais, que ditam as normas a serem seguidas por todos do grupo.

Mais uma vez, o problema se encontra na negação da dimensão do político e na ideia de que o objetivo da política é estabelecer o consenso em um único modelo, impedindo a possibilidade de um dissenso legítimo. Portanto, o terrorismo realça os perigos das falácias do discurso universalista globalizado, que postula que o progresso humano requer o estabelecimento de uma unidade mundial baseada na implementação do modelo ocidental.

Sendo assim, o fim da ordem mundial bipolar não conduziu a um sistema mais harmonioso, mas sim a explosão de uma diversidade de novos antagonismos. E como escapar desse círculo vicioso? Para Mouffe (2001), é necessário romper com a convicção de que as sociedades ocidentais possuem o melhor

\footnotetext{
${ }^{6} \mathrm{Na}$ Áustria, por exemplo, o consenso no centro se estabeleceu pouco depois da Segunda Guerra Mundial mediante a criação de uma grande coalizão entre o conservador Partido do Povo (ÖVP) e o Partido Socialista (SPÖ). E com a vitória de Jorg Haider, vários países passaram a demonizar a extrema direita austríaca.
} 
regime e que têm a missão civilizadora de universalizá-lo ${ }^{7}$, questionando a crença na superioridade única da democracia liberal.

Archibugui e Held (1995) destacam a preponderância da democracia, que deve se impor globalmente por meio da criação de instituições internacionais que permitam que os indivíduos tenham influência nos assuntos globais, o que conota seu caráter cosmopolita. Por conseguinte, o direito da democracia deve ser internacionalizado com vistas ao estabelecimento de uma comunidade cosmopolita, cujos Estados devem se articular dentro de um direito democrático global. Contudo, as formas cosmopolitas de justiça e de proteção dos direitos implicam a elaboração e execução de normas legitimadas desde uma perspectiva parcial e ocidental, resultando na imposição de um único modelo, o democrático liberal, sobre toda a ordem mundial - o que, segundo Mouffe, despertaria fortes resistências e antagonismos.

O rompimento do modelo cosmopolita de democracia, que impõe o modelo democrático liberal em razão da ordem multipolar, despertando fortes resistências e antagonismos, somente seria possível através da criação do modelo agonista de conflito. O verdadeiro desafio da política democrática no plano internacional e doméstico não é a superação da relação nós/eles, mas a concepção de formas de construção do binômio compatíveis com uma ordem pluralista e multicultural.

Sendo assim, é preciso aceitar o pluralismo e as múltiplas identidades, renunciando a ilusão de um mundo unificado, com identidade única, e trabalhando para o estabelecimento de um mundo multipolar onde exista uma pluralidade de centros de decisão e equilíbrio entre diversos poderes. É necessário o estabelecimento de um equilíbrio entre polos regionais cujas tradições e interesses específicos sejam considerados como valiosos e aceitos como diferentes modelos genuínos de democracia. Tanto a esquerda quanto a direita devem reconhecer o caráter pluralista do mundo e adotar uma perspectiva multipolar, com estabelecimento de um sistema de direito internacional baseado na ideia de pólos regionais e identidades culturais, com reconhecimento de sua total autonomia.

Acima de tudo, o fortalecimento da dimensão antagônica do conflito perpassa pelo revigoramento da questão das identidades culturais em suas articulações com a globalização. As antigas identidades consensuais estão em declínio, dando espaço a novas identidades que fragmentam o indivíduo moderno (HALL, 2004), não sendo mais possível uma única forma de democracia consensual pensada para toda uma ordem mundial. Se anteriormente o sujeito "tinha experiência de uma identidade unificada e estável, está se tornando fragmentado; composto, não de uma, mas de muitas identidades" (ibid., p. 11), transformando as sociedades modernas e fragmentando os cenários culturais de classe, gênero, etnia, raça e nacionalidade.

O self do iluminismo era pautado na ideia do indivíduo como centrado e unificado, dotado de razão (ou seja, o sujeito cartesiano). Entretanto, à medida que as sociedades modernas cresceram, elas adquiriram uma forma mais coletiva e social. Surgiu, então, uma concepção mais social do sujeito, no qual "o indivíduo passou a ser visto como mais localizado e instalado no interior dessas grandes estruturas e formações de sustentação da sociedade moderna" (ibid, p. 24). Com isso, o self sociológico é formado em relação a outros significados, ou seja, a interação entre o sujeito e a sociedade. Por fim, o sujeito pós-moderno é isento de identidade fixa, assumindo diferentes identidades em momentos diversos em razão das rápidas mudanças das sociedades globalizadas. Consequentemente, o sujeito do

\footnotetext{
${ }^{7}$ Novamente, Mouffe critica Habermas, que busca estabelecer a natureza racional da democracia liberal e sua validez universal, sendo que toda oposição é considerada como um símbolo de irracionalidade e atraso moral. Sendo assim, todas as sociedades deveriam adotar instituições democráticas liberais.
} 
Iluminismo, com identidade fixa e estável, foi descentrado nas identidades inacabadas e fragmentadas do sujeito pós-moderno.

As paisagens políticas do mundo moderno estão cada vez mais fraturadas por identificações que competem entre si, aumentando o componente conflitual. As identidades, por sua vez, nunca foram tão unificadas ou homogêneas a ponto do modelo consensual de democracia ser aplicável a todas as formas de sociedade, de maneira que a formação de identidades minoritárias dentro de estados nacionais levou à pluralização de culturas e identidades nacionais. Assim, a "tendência em direção à homogeneização global, portanto, compete com um poderoso ressurgimento da etnicidade" (HALL, p. 77).

O enfoque agonista, portanto, não pretende abarcar todas as diferenças e superar todas as formas de exclusão. Mas as exclusões devem ser definidas em termos políticos, e não morais. Sendo assim, é necessário abandonar o princípio eurocêntrico segundo o qual o modelo democrático liberal tem um título exclusivo sobre a racionalidade e a moralidade sobre todas as identidades culturais. Sem dúvida, em um mundo multipolar e multicultural, os conflitos continuam existindo. Mas é necessário reconhecer o político em sua dimensão antagônica, abandonando a ilusão de um mundo reconciliado no qual o poder, a soberania e a hegemonia seriam superados. E graças à ideia de adversário, o enfoque agonista pode contribuir a uma revitalização da democracia.

\section{CONCLUSÃO}

A teoria habermasiana de democracia estipulou a deliberação intersubjetiva como um dos alicerces para a construção do consenso, enfatizando o papel da linguagem e do discurso na construção de um projeto político ideal. Anos depois, Honneth e Fraser partiram de alguns pressupostos habermasianos para discutir a questão do reconhecimento e da redistribuição, inserindo o discurso nesse novo âmbito de análise.

No entanto, a teoria pós-moderna da democracia de Mouffe (2009) apontou que a política democrática não deve superar a discriminação nós/eles mediante o consenso - pois todo consenso (crítica a Habermas) não passa de um resultado hegemônico do poder - mas consiste em ativar uma confrontação democrática, onde a noção de antagonismo desempenha um papel central.

Em linhas gerais, o antagonismo é a impossibilidade da constituição objetiva e necessária de uma totalidade discursiva, pois existe a presença de um discurso antagônico que impede essa constituição plena. Portanto, o ponto fundamental para o entendimento da relação antagônica é que ela ocorre entre um exterior constitutivo que ameaça a existência de um interior.

Dessa maneira, o projeto político defendido por Mouffe (2009) é a transformação das relações antagônicas em agônicas e a superação da relação entre inimigos (antagonismo) para uma relação entre adversários (agonismo), já que as relações de poder são constituidoras da política. O ponto fundamental da noção de agonismo não é a competição ou a disputa, mas a existência de regras onde os adversários lutam a partir de um ponto comum, de modo que a disputa não ocorra com o fim de destruir o oponente, mas sim pela legitimidade de um discurso em detrimento de outro. Além disso, enquanto no antagonismo não há medida comum entre interior e exterior e os discursos promovem uma luta entre inimigos, no agonismo existe uma medida comum entre as diferentes formações discursivas, um universal mínimo - o reconhecimento da legitimidade da existência do discurso concorrente. Além disso, na relação agônica a categoria de inimigo é substituída pela de adversário.

Para Mouffe (1993), o mérito do pós-modernismo está em sua crítica da subjetividade moderna, em sua insistência em descentralizar ou desconstruir o ego moderno cartesiano e coletivo. Entretanto, 
tal desconstrução não deve anular a ação humana - o que deixaria a democracia se render aos caprichos do mercado. Muito então depende do tipo de descentralização contemplada pelos defensores da democracia radical. Para Dallmayr (2001), a verdadeira descentralização só pode ocorrer quando o agente humano (eu) fica exposto a um outro ou a outros, a quem questiona e por quem, em troca, é questionado.

Essa visão de democracia como uma autotransformação tem implicações importantes. Em primeiro lugar, a ênfase dada pelos pós-modernos à descentralização traz à tona premissas antropocêntricas e egocêntricas. Em segundo lugar, a política multicultural rejeita a uniformização de grupos culturais ou étnicos, reconhecendo sua legítima diferença e recusando-se a uniformizá-los em um gesto agressivo de apropriação. Dessa maneira, a partir da teoria pós-moderna, podemos observar que a principal tarefa da teoria democrática é de repensar o governo popular de forma a fugir dos encantos da soberania ou da identidade coletiva, sem invalidar ou se desviar do governo popular para privilegiar o mercado e o liberalismo de cooperação.

\section{REFERÊNCIAS}

ARCHIBUGUI, D.; HELD, D. Cosmopolitan Democracy: An Agenda for a New World Order. Cambridge: Polity Press, 1995

AVRITZER, L. A Moralidade da Democracia: Ensaios em Teoria Habermasiana e Teoria Democrática. Belo Horizonte: UFMG, 1996.

BECK, U. The Reinvention of Politics: Rethinking Modernity in the Global Social Order. Cambridge: Polity Press, 1997.

DALLMAYR, F. "Para além da democracia fugidia: algumas reflexões modernas e pós-modernas". Em Jessé Souza (org.), Democracia hoje: novos desafios para a teoria democrática contemporânea. Brasília: UnB, 2001.

FRASER, N. "From distribution to recognition? Dilemmas of Justice in a Postsocialist Age", em Fraser (ed.), Justice Interruptus: Critical Reflections on the Postsocialist Condition. Londres: Routledge, 1997.

FRASER, N. "Da distribuição ao reconhecimento". Em Jessé Souza (org.), Democracia hoje: novos desafios para a teoria democrática contemporânea. Brasília: UnB, 2001.

FREITAG, B. A Teoria Crítica: Ontem e Hoje. São Paulo: Brasiliense, 1986.

GIDDENS, A. As Consequências da Modernidade. São Paulo: Unesp, 1991.

GIDDENS, A. Más Allá de La izquierda y La derecha. Madrid: Cátedra, 1997.

GIDDENS, A. La tercera vía. Madrid: Taurus, 2002.

HABERMAS, J. Teoria de la Acción Comunicativa. Madrid: Taurus, 2001.

HABERMAS, J. Mudança Estrutural da Esfera Pública. Rio de Janeiro: Tempo Brasileiro, 2003.

HABERMAS, J. A Inclusão do Outro. São Paulo: Edições Loyola, 2004.

HALL, S. A Identidade Cultural na Pós-Modernidade. Rio de Janeiro: DP\&A, 2004. 
HONNETH, A. Luta por Reconhecimento: a Gramática Moral dos Conflitos Sociais. São Paulo: Editora 34, 2003.

LACLAU, E.; MOUFFE, C. Hegemony and Social Strategy: Towards a Radical Democratic Politics. Londres: Verso, 1985.

MENDONÇA, D. d. A noção de antagonismo na ciência política contemporânea: uma análise a partir da perspectiva da teoria do discurso. Revista de Sociologia e Política, Curitiba, 20, p.135-145, junho de 2003.

MENDONÇA, R. Reconhecimento em debate: os modelos de Honneth e Fraser em sua relação com o legado habermasiano. Revista de Sociologia e Política, Curitiba, 29, p.169-185, novembro de 2007.

MOUFFE, C. The Return of the Political. Londres: Verso, 1993.

MOUFFE, C. En torno a lo político. Buenos Aires: Fondo de Cultura Económica, 2009.

SCHMITT, C. El concepto de lo político. Madrid: Alianza, 1998. 